\title{
First infection by all four non-severe acute respiratory syndrome human coronaviruses takes place during childhood
}

\author{
Weimin Zhou, Wen Wang, Huijuan Wang, Roujian Lu and Wenjie Tan ${ }^{*}$
}

\begin{abstract}
Background: Non-severe acute respiratory syndrome (non-SARS)-related human coronaviruses (HCoVs), including HCoV-229E, -HKU1, -NL63, and -OC43, have been detected in respiratory tract samples from children and adults. However, the natural prevalence of antibodies against these viruses in serum among population is unknown.

Methods: To measure antibodies to the spike (S) protein of the four common non-SARS HCoVs, recombinant $\mathrm{S}$ proteins of the four HCoVs were expressed and characterised in $293 \mathrm{~T}$ cell. An S-protein-based indirect immunofluorescence assay (IFA) was then developed to detect anti-S IgG and IgM for the four individual HCoVs and applied to serum samples from a general asymptomatic population (218 children and 576 adults) in Beijing.

Results: Of 794 blood samples tested, only 29 (3.65\%) were negative for anti-S IgG. The seropositivity of the four anti-S IgG antibodies was $>70 \%$ within the general population. The majority of seroconversions to four-HCoV positivity first occurred in children. Both S-IgG and S-IgM antibodies were detectable among children and increased with age, reaching a plateau at 6 years of age. However, no anti-S IgM was detected in healthy adults.

Conclusion: Large proportions of children and adults in Beijing have evidence of anti-S IgG against four the HCoVs, and first infections by all four non-SARS HCoVs takes place during childhood.
\end{abstract}

Keywords: Human coronavirus, Spike protein, Indirect immunofluorescence assay, Antibody

\section{Background}

Coronaviruses are positive-sense, single-stranded RNA viruses found in humans and a wide variety of animals [1]. In humans, four respiratory coronaviruses, namely human coronavirus (HCoV) -229E [2], -OC43 [3], -NL63 [4], and -HKU1 [5], are endemic worldwide. These four common strains cause diseases from mild, febrile upper respiratory tract illnesses to severe outcomes, such as croup, bronchiolitis, and pneumonia, and attribute to about $10 \%$ of all upper and lower respiratory tract infections in hospitalised children [1,6]. In 2003, a previously unknown coronavirus caused an outbreak of severe acute respiratory syndrome (SARS) in humans $[7,8]$. More recently, the novel betacoronavirus species HCoV-EMC was identified from a man with pneumonia in Saudi Arabia [9].

\footnotetext{
* Correspondence: tanwj28@yahoo.cn

Key Laboratory of Medical Virology, Ministry of Health; National Institute for Viral Disease Control and Prevention, China Centers for Disease Control and Prevention, Beijing 102206, China
}

(c) 2013 Zhou et al.; licensee BioMed Central Ltd. This is an Open Access article distributed under the terms of the Creative Commons Attribution License (http://creativecommons.org/licenses/by/2.0), which permits unrestricted use, distribution, and reproduction in any medium, provided the original work is properly cited.

Coronaviruses are phenotypically and genotypically diverse [6,10]. All coronaviruses possess a common genome organisation in which the replicase gene encompassing the 5 two-thirds of the genome is comprised of two overlapping open reading frames, ORF1a and ORF1b. The structural gene region, which covers the 3 ' third of the genome, encodes the canonical set of structural protein genes in the order 5 '-spike $(\mathrm{S}) \rightarrow$ envelope $(\mathrm{E}) \rightarrow$ membrane $(\mathrm{M}) \rightarrow$ nucleocapsid $(\mathrm{N})-3^{\prime}[1,10]$. The $\mathrm{S}$ proteins is the most immunodominant $\mathrm{CoV}$ protein $[1,6,10]$.

The most common method for diagnosing $\mathrm{HCoV}$ infection is reverse transcription polymerase chain reaction (RT-PCR) or real-time RT-PCR using RNA extracted from respiratory tract samples, such as nasopharyngeal aspirates $[6,11,12]$. On the other hand, serological assays for detection of antibody to $\mathrm{HCoV}$ are more complex to establish $[1,6]$. However, determining the levels of immunoglobulin M (IgM) and immunoglobulin G (IgG) antibodies in appropriate serum or plasma samples allows the researcher 
to define the point in time of primary infection as well as exposure rates; seroepidemiological studies are also important tools for $\mathrm{HCoV}$ infection diagnosis and research [6,13-17]. Previous reports have indicated that immunofluorescence assays (IFAs) for the detection of seroconversion with IgG antibodies against the main structural (N and S) proteins of SARS-CoV are useful for the diagnosis of acute SARS-CoV infection [18,19]. Little is currently known about the prevalence of anti-S antibodies specific for non-SARS HCoV infection among children and adults. We propose that an IFA for the detection of IgG against structural ( $\mathrm{N}$ and $\mathrm{S}$ ) proteins of non-SARS HCoV may be suitable for seroepidemiological studies.

To expand the epidemiological knowledge of four nonSARS-related endemic HCoVs in China, we expressed $\mathrm{S}$ proteins in a eukaryotic system and established an IFA for the detection of IgG or IgM antibodies against these four viruses. We used this system to determine the prevalence of anti-S IgG and IgM antibodies against HCoVs among a general population in Beijing.

\section{Methods \\ Study population}

794 serum samples were obtained from a general asymptomatic population (6 months to 75 years of age) who visited hospitals for medical examinations or vaccinations in Beijing from 1999 to 2011. All aspects of this study were performed in accordance with the national ethics regulations and approved by the Institutional Review Boards of the Centre for Disease Control and Prevention of China and the Ethics Committee of Peking Union Medical College Hospital. Participants received written information regarding the purpose of the study and of their right to confidentiality. Written informed consent was obtained from all participants or their guardians.

\section{Construction of HCoV-S expression plasmids}

$\mathrm{S}$-protein-coding gene optimisation was conducted and oligonucleotides synthesised (Qingke Bio-Tech Engineering Service Co., Ltd., Beijing) according to the $\mathrm{S}$-protein sequences of four non-SARS-related endemic HCoVs in GenBank (229ENC_002645, OC43NC_005147, HKU1NC_006577, and NL63NC_005831). The leader sequence of the original gene was removed and replaced by a human TPA leader sequence (1-21 aa) at the $\mathrm{N}$-terminal of the $\mathrm{S}$ fragment. Artificially synthesised $\mathrm{S}$ fragments of HCoV-OC43, -229E, -HKU1, and -NL63 were cloned into the eukaryotic expression plasmid pVRC (a gift from Dr. Gary Nabel, NIH, USA) and named pVRC-229E-S, -OC43-S, -HKU1-S, and -NL63-S, respectively (Figure 1A). The plasmid pVRC-8304 (from Dr. Gary Nabel, NIH, USA) [20], in which the S-protein-coding gene of SARS-CoV was constructed and used as a DNA vaccine, was used as the control.
Preparation of mouse anti-S sera by DNA immunisation Female BALB/c (H-2d) mice between 6 and 8 weeks of age (Animal Care Centre, Chinese Academy of Medical Science, Beijing, China) were randomly assigned to four groups. In accordance with the Institutional Animal Care and Use Committee (IACUC)-approved protocol, all mice were immunised at weeks 0,3 , and 6 and bled at week 8 . The mice were anaesthetised and primed with the above S-expression plasmid using intradermal injection into the lower dorsal side $(10 \mu \mathrm{g} / 30 \mu \mathrm{L})$. Gene delivery using in vivo electroporation was performed as described previously [21]. Serum samples were collected 2 weeks after the last vaccination, and the pooled anti-S serum against individual $\mathrm{HCoVs}$ was stored at $-70^{\circ} \mathrm{C}$.

\section{Western blotting}

293FT cells were transfected with individual S-expression plasmids using Lipofectinamine2000 reagent (Invitrogen Company). At $36 \mathrm{~h}$ post-transfection, the cells were lysed in ice-cold RIPA buffer (50 mM Tris-HCl [pH 7.5], $150 \mathrm{mM} \mathrm{NaCl}, 1 \%$ Triton X-100, 0.1\% SDS, and 0.5\% sodium deoxycholate) supplemented with a protease inhibitor mixture (Sigma, St. Louis, MO). The lysates were kept on ice for $10 \mathrm{~min}$, centrifuged, and resolved by SDS/PAGE in a $6 \%$ polyacrylamide gel. The proteins were transferred to a nitrocellulose membrane, blocked with 5\% skim milk in PBS for $2 \mathrm{~h}$, and incubated for $8 \mathrm{~h}$ at $4^{\circ} \mathrm{C}$ with anti-S mouse polyclonal antibody diluted to $1: 50$ in blocking buffer. The membrane was washed in PBS containing Tween $20(0.1 \%)$ and incubated for $1 \mathrm{~h}$ with horseradish peroxidase-conjugated anti-mouse secondary antibody (Pierce, Rockford, IL) diluted to 1:5000. The membrane was washed and the proteins were visualised with SuperSignal Chemiluminescence Substrate (Pierce).

\section{Indirect IFA}

An IFA was used to detect $\mathrm{HCoV} S$ glycoprotein expression in 293 T cells. Briefly, 293 T cells seeded on glass slides were transfected with pVRC-229E-S, -OC43-S, -HKU1-S, and -NL63-S plasmids, respectively. After a 36 -h incubation at $37^{\circ} \mathrm{C}$ in $5 \% \mathrm{CO}_{2}$, the cells were fixed in $2 \%$ paraformaldehyde and blocked in $5 \%$ normal goat blood serum in 1\% Triton-X-100 PBS. The infected cells were incubated with anti-S mouse serum (1:500) for $1 \mathrm{~h}$, and then incubated with FITC-labelled goat anti-mouse IgG ( $\mathrm{H}+\mathrm{L}$; Zhongahan Co., Beijing, China) for $30 \mathrm{~min}$. Positive foci were identified by fluorescence microscopy (Nikon, Tokyo, Japan) after Evans blue duplicate staining.

For serum anti-S IgG or IgM detection using IFA, an individual $\mathrm{HCoV} S$ glycoprotein expression plasmid was used to transfect the $293 \mathrm{FT}$ cells in the $75-\mathrm{cm}^{2}$ flask. Forty-eight hours later, the transfected cells were washed twice with PBS and then dripped onto the slide. The cells were fixed using $4 \%$ paraformaldehyde for $10 \mathrm{~min}$, 

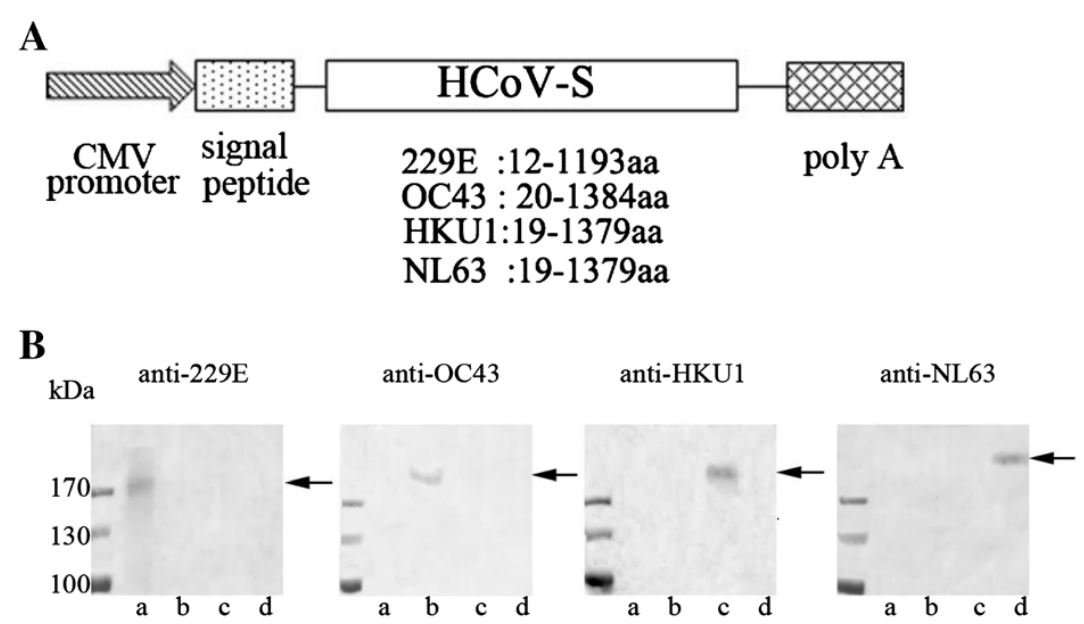

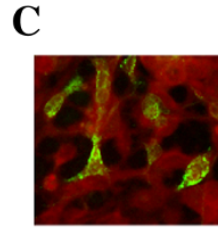

a

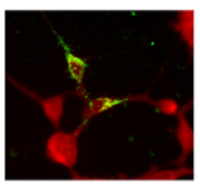

b

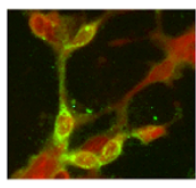

C

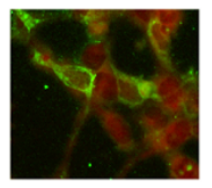

d

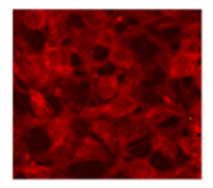

control

Figure 1 Construction and characterization of spike expression plasmids derived from non-SARS HCoVs. (A) Construction scheme of spike (S) fragment expression plasmids derived from four individual HCoVs (-229E, -OC43, -NL63, and -HKU1). (B) Characterisation of S proteins of individual HCoV expression plasmids by western blot using anti-S mouse serum from DNA vaccination. Forty-eight hours after 293 T cell transfection with the above individual HCoV expression plasmids, the cell lysates were collected for SDS-PAGE and western blot. (C) Characterisation of S protein by indirect immune fluorescence assay (IFA) using anti-S serum from mice immunised with individual HCoV expression plasmids. The control was transfected with pVRC-8303 plasmid and detected with mixed anti-S mouse serum of a non-SARS CoV.

then permeabilised using $0.2 \%$ TritonX-100 and washed three times with PBS. The anti-S-specific antibodies in sera (diluted to 1:20) were quantified using 1:100-diluted FITC-labelled sheep anti-human IgG ( $\mathrm{H}+\mathrm{L}$; Zhongahan Co., Beijing, China) or 1:40-diluted FITC-labelled antihuman IgM ( $\mu$-chain-specific), and the slide was viewed under an inverted fluorescence microscope (Olympus, Tokyo, Japan). Serum samples that reacted with $\mathrm{HCoV}$ $\mathrm{S}$ protein at a dilution of $>1: 20$ were considered positive for anti-S antibodies when duplicate or triple test was consistent. Furthermore, we confirmed that non-transfected 293 T cells or those transfected with the control plasmid (pVRC8304, which expresses the S protein of SARS$\mathrm{CoV}$ ) did not react with the human serum samples tested.

\section{Statistical analysis}

Statistical analysis was performed using the Statistic Package for Social Science(SPSS) statistic 17 package with $\chi^{2}$-test and Fisher's exact test. Differences between the mean values of each group were considered significant at $\mathrm{p}<0.05$ when assessed using Tukey's test.

\section{Results}

Population characteristics

The demographic characteristics of the study subjects are summarised in Table 1. Of 794 patients subjects studied, $215(27.08 \%)$ were infants or children $<14$ years of age; 457 (57.55\%) were male. The average age of the adults and children was $28.75 \pm 17.79$ years. The majority of patients in the child population were 1 to 3 years of age $(n=134,61.47 \%)$, and the majority of adults were 31 to 50 years of age $(n=363,63.0 \%)$.

\section{Construction and characterisation of HCoV-S expression plasmids}

The structures of the S-fragments of individual $\mathrm{HCoV}$ expression constructs used in this study are summarised in Figure 1A. Expression of the $\mathrm{HCoV} \mathrm{S}$ proteins was confirmed by western blotting (Figure 1B). The segments were detected by anti-S mouse serum derived from DNA vaccination with individual $\mathrm{HCoV}$ S-expression plasmids. All four non-SARS-related S proteins showed band sizes that were consistent with the predicted molecular mass (150-200 kDa), presumably reflecting glycosylated forms of $\mathrm{S}$ protein. In addition, the expression of 
Table 1 Demographic characteristics and anti-S IgG detection of the study subjects

\begin{tabular}{|c|c|c|c|}
\hline \multicolumn{2}{|l|}{ Characteristic } & Value (male/female) & $\%$ \\
\hline \multicolumn{2}{|l|}{ No. of subjects } & $794(457 / 337)$ & \\
\hline \multicolumn{2}{|l|}{ Mean age $(y)$} & $28.75 \pm 17.79$ & \\
\hline \multicolumn{2}{|l|}{ Age range $(y)$} & $0.5-75$ & \\
\hline \multicolumn{4}{|l|}{ Group } \\
\hline \multirow[t]{5}{*}{ Child (<14 y) } & & $215(113 / 102)$ & \\
\hline & $<1 \mathrm{y}$ & $8(5 / 3)$ & \\
\hline & $1-3 y$ & $134(68 / 66)$ & \\
\hline & $3-6 y$ & $46(28 / 18)$ & \\
\hline & $7-14 y$ & $27(12 / 15)$ & \\
\hline \multirow[t]{5}{*}{ Adult ( $\geq 14$ y) } & & $579(344 / 235)$ & \\
\hline & $15-30 y$ & $150(76 / 74)$ & \\
\hline & $31-40 y$ & $211(132 / 79)$ & \\
\hline & $41-50 y$ & $152(91 / 61)$ & \\
\hline & $\geq 51$ y & $66(45 / 21)$ & \\
\hline \multirow[t]{4}{*}{ Any lgG (+) } & $229 \mathrm{E}$ & 665 & 83.75 \\
\hline & OC43 & 590 & 74.31 \\
\hline & HKU1 & 549 & 69.14 \\
\hline & NL63 & 580 & 73.05 \\
\hline \multicolumn{2}{|l|}{ All (-) } & 29 & 3.65 \\
\hline
\end{tabular}

recombinant $\mathrm{HCoV} S$ proteins was further confirmed by immunofluorescence staining using specific anti-S mouse serum, as noted above (Figure $1 C$ ). All S proteins were expressed mainly in the cytoplasm and membrane. No cross-staining was observed when other $\mathrm{HCoV}$ antiserum was used as the primary antibody, specifically concerning virus-antibody pairs of subgroup 229E/NL63 (alphacoronaviruses) or OC43/HKU1(batacoronaviruses). Furthermore, no false positive/negative result was observed in our study (data not shown).

\section{Prevalence of anti-S IgG according to age group}

A representative anti-S-positive IFA result is shown in Figure 2. Using IFA based on 293FT cells expressing individual $\mathrm{S}$ proteins of $\mathrm{HCoV}$, we investigated the seroprevalence of these viruses in serum from various age groups of a healthy population in Beijing. All samples were tested three using IFA and the result showed well reproducibility.

Of 794 serum samples tested for anti-S IgG by IFA, only 29 (3.65\%) were negative for anti-S IgG of HCoV (Table 1). $665(83.75 \%)$ serum samples were positive for $\mathrm{HCoV}-$ 229E, 580 (73.05\%) for HCoV-NL63, 590 (74.31\%) for $\mathrm{HCoV}-\mathrm{OC} 43$, and 549 (69.14\%) for HCoV-HKU1. There were no significant differences between genders.

The distribution and variation trend of anti-S IgG to the four HCoVs among the age groups are shown in Figure 3. The seropositivity rate was $70.15 \%$ for $\mathrm{HCoV}-229 \mathrm{E}$ and $62.69 \%$ for $\mathrm{HCoV}-\mathrm{OC} 43$, which are similar to the levels of HCoV-HKU1 (58.21\%) and HCoV-NL63 (60\%) among the 1 - to 3-year-old group $(p>0.05)$. The proportions of $\mathrm{HCoV}$ IgG-positive samples increased with age during infancy, reaching levels $>75 \%$ at age $>4$ years. Interesting, a significant drop in seropositivity rate was observed for $\mathrm{HCoV}$-OC43 in the 15- to 30-year-old group and for $\mathrm{HCoV}-\mathrm{HKU} 1$ in the 7 - to 14-year-old group. In the child population $(n=218)$, the total positivity rate of anti-S IgG antibodies was $73.85 \%$ for $229 \mathrm{E}, 68.81 \%$ for OC43, 61.93\% for HKU1, and $66.51 \%$ for NL63 (Figure 3); no significant differences were observed with regard to IgG to two novel HCoVs among the children (NL63, $p=0.051$; HKU1, $p=0.329$ ).

In the adult population ( $\geq 14$ years of age), the seroprevalence of anti-S IgG of HCoV-229E, -OC43, and -NL-63 did not differ significantly among the age groups $(229 \mathrm{E}$, $p=0.323$; NL63, $p=0.545$; OC43, $p=0.204)$. For HCoVHKU1, a significant increase in the seroprevalence rate with increasing age was observed $(p=0.025)$. In the adult population $(n=576)$, the IgG positivity rate was 87.5\% for 229E, $76.39 \%$ for OC43, $71.88 \%$ for HKU1, and $75.52 \%$ for NL63. The proportion of subjects with detectable IgG antibodies to HCoV-229E was significantly greater than that to -OC43 and -NL63 $(p<0.05)$. Furthermore, the number of subjects with IgG to the three above-mentioned $\mathrm{HCoVs}$ was also significantly greater than that to HCoV-HKU1 $(p<0.05)$. However, there were no significant differences in the anti-S IgG

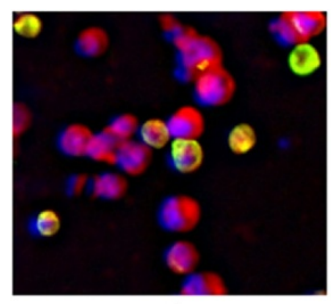

A

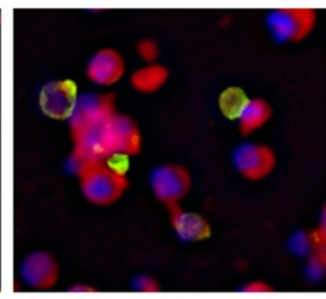

B

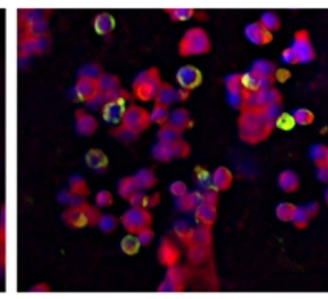

C

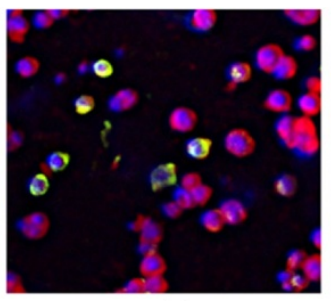

D

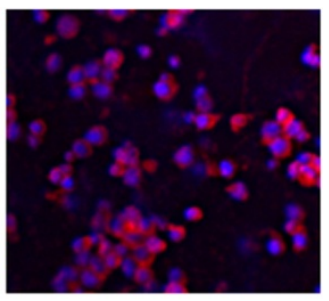

control

Figure 2 Representative IFA for detection of anti-S antibodies of non-SARS HCoVs in human serum. A, 229E-S expression plasmid; B, OC43-S expression plasmid; C, HKU1-S expression plasmid; D, NL63-S expression plasmid; control, mock plasmid pVRC-8304. 
A



B

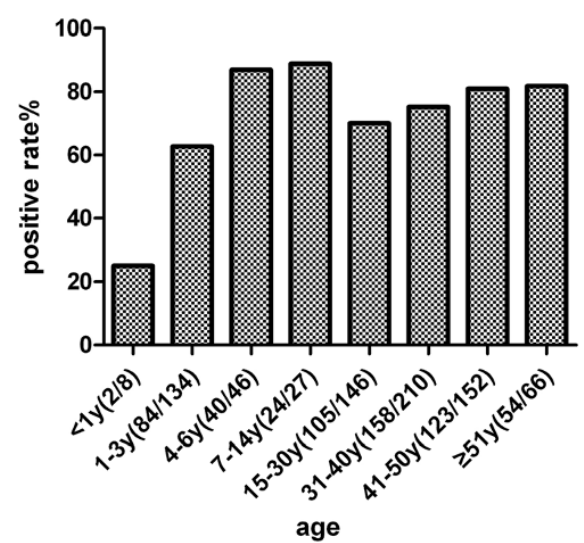

C

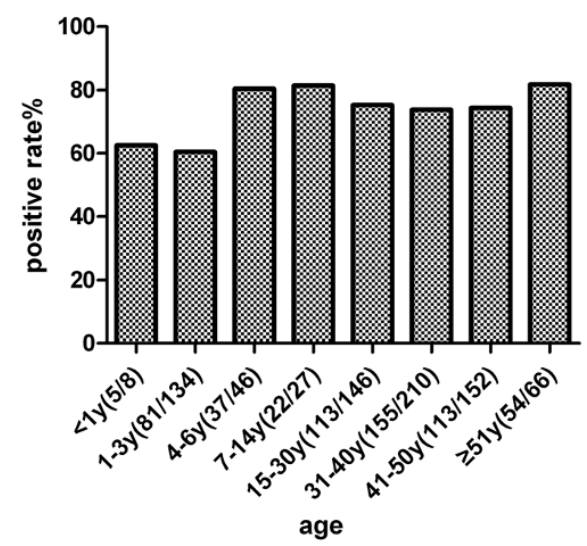

D

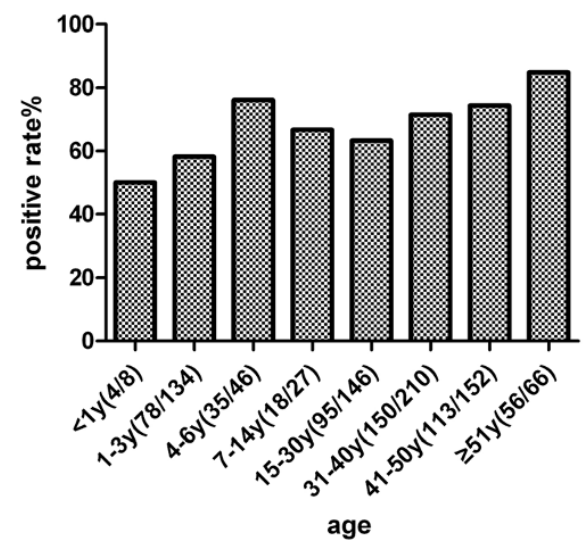

Figure 3 Anti-S IgG positivity rate of individual HCoVs according to age group. (A) Anti-S IgG positivity rates for HCoV-229E; (B) Anti-S IgG positivity rates for HCoV-OC43; (C) Anti-S IgG positivity rates for HCoV-HKU1; (D) Anti-S IgG positivity rates for HCoV-NL63.

seropositivity rates of individual $\mathrm{HCoVs}$ with respect to gender in either the child or adult population (Data not shown).

\section{Anti-S IgM detection in children}

The prevalence and variation trend of anti-S IgM antibodies to individual HCoVs among the child population is shown in Figure 4. The total positivity rate of anti-S IgM was $36.24 \%$ for $229 \mathrm{E}, 43.12 \%$ for OC43, $54.46 \%$ for HKU1, and $44.50 \%$ for NL63. The anti-S IgM positivity rate of $\mathrm{HCoV}-229 \mathrm{E}$ was significantly lower than that of the other three HCoVs $(p=0.028)$, while there were no significant differences in the anti-S IgM seropositivity rates of individual $\mathrm{HCoVs}$ with respect to gender (Data not shown).

There was a significant difference in the anti-S IgM positivity rate for individual $\mathrm{HCoVs}$ among age groups. The anti-S IgM positivity rate of HCoV-HKU1 was significantly higher than that of the other three HCoVs among the $<3$-year-old groups (Figure 4). The positivity rate increased with age and began to drop after peaking in the school-age group ( $\geq 6$ years), which is similar to that described above for anti-S IgG detection. No anti-S IgM antibodies for the four individual $\mathrm{HCoVs}$ were detected in the serum of the healthy adult population $>15$ years of age.

\section{Discussion}

This is the first comprehensive study to evaluate anti-S IgG and IgM for four non-SARS HCoVs among the general population in China. We first time show that anti-S IgM is only present in children, indicating that for all viruses first infection takes place during childhood (age $<14$ years).

The SARS epidemic that originated from southern China in 2003 sparked interest in all areas of coronavirus research [4-9]. Four endemic non-SARS-related HCoVs (HCoVOC43,-229E,-NL63 and -HKU1) are major contributors to respiratory tract infections and other clinical manifestations [6,11-17,22]. However, specific and feasible serological surveys of these $\mathrm{HCoVs}$, especially for HCoV-NL63 


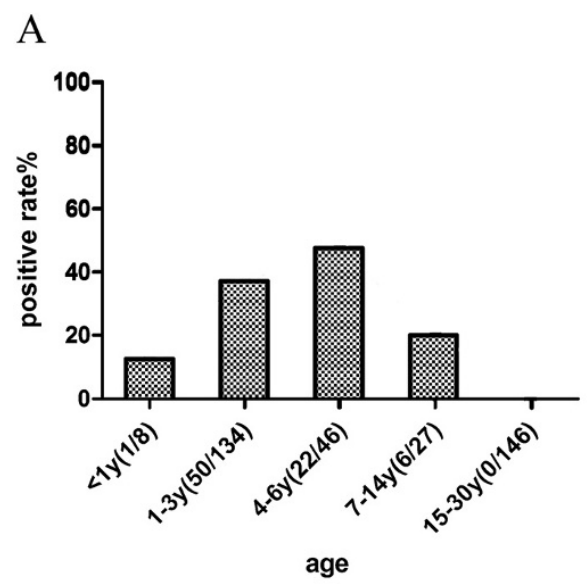

B

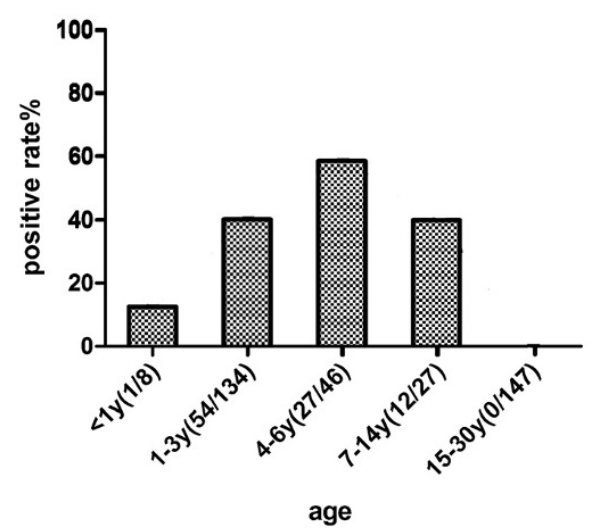

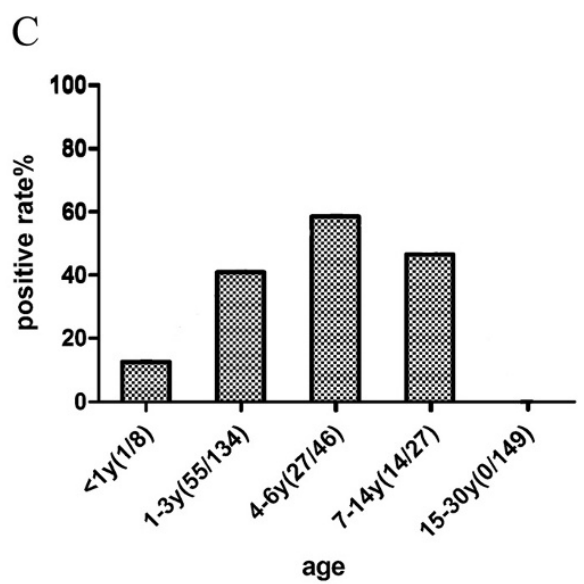

D

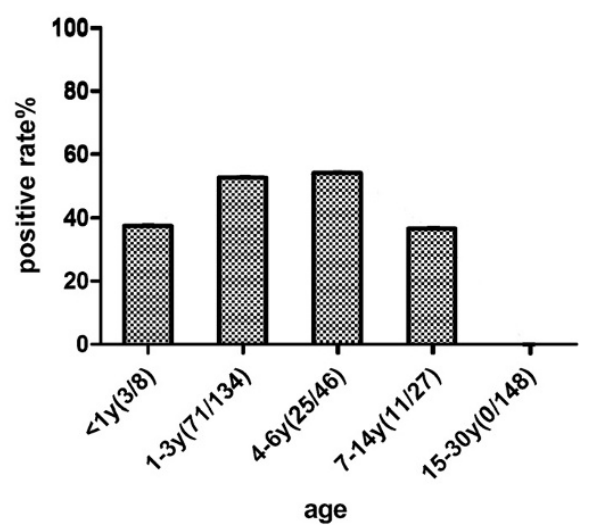

Figure 4 Anti-S IgM positivity rates of individual HCoVs according to age group. (A) Anti-S IgM positivity rates for HCoV-229E; (B) Anti-S IgM positivity rates for HCoV-OC43; (C) Anti-S IgM positivity rates for HCoV-NL63. (D) Anti-S IgM positivity rates for HCoV-HKU1.

and -HKU1, have to date been reported among the general population only rarely in China. Spike is the major structural protein of $\mathrm{HCoVs}[1,10]$. It contains multiple conformational epitopes that are major inducers of antibody neutralisation, and it has the lowest sequence conservation among coronavirus proteins, rendering it a specific target for serodiagnosis $[1,10,23-26]$. We chose the HCoV S gene for recombinant expression on the basis of current knowledge of immunodominant SARS-CoV antigens, which belongs to the same virus family as $\mathrm{HCoV}$. Previous studies of SARS-CoV serology have successfully used the $\mathrm{S}$ protein in enzyme immunoassays, immunoblots, and IFA [23-27]. In addition, comparison of the $\mathrm{S}$ protein sequences of four $\mathrm{HCoVs}$ revealed that these proteins share $<35 \%$ similarity $[1,10]$. We hypothesised that the difference in the amino acid sequence is sufficiently high to ensure the usefulness of $\mathrm{S}$ protein as a specific antigen for antibody detection. The native surface $\mathrm{S}$ protein expressed in $293 \mathrm{~T}$ cells can be recognised in post-infection population serum by IFA. Some reports indicated that this cell-based $\mathrm{S}$ protein expression system can differentiate false-positive ELISA results using the more cross-reactive nucleoprotein antigen $[18,24]$. Furthermore, Woo et al. reported that the rSbased IgM ELISA is more sensitive than the rN-based IgM ELISA for SARS-CoV pneumonia [25]. Our results showed that the S-based IFA enabled specific detection of IgG or IgM to four individual HCoVs.

Using IFA, we investigated the natural seroprevalence of four non-SARS-related HCoVs in blood samples from a general population that comprised a variety of age groups. Anti-S IgG antibodies to these four non-SARS-related $\mathrm{HCoVs}$ were detected at high rates $(>70 \%)$ among healthy adults. Both anti-S IgG and IgM antibodies were found in the child group, and their prevalence increased with age up to 6 years, at which point it almost plateaued. These data suggest that exposure to $\mathrm{HCoV}$ is common in childhood and first infections by all four non-SARS HCoVs takes place during children. Moreover, we found evidence of anti-S IgG against double and multiple HCoVs in various combinations, which indicates that large proportions of the general population in Beijing may experience infections with more than one $\mathrm{HCoV}$. 
The seroprevalence of $\mathrm{HCoV}$ antibodies varies widely among studies, which used different antigens and methodologies [6,13-18,26-33]. Previous studies of non-SARS $\mathrm{HCoVs}$ demonstrated that seroprevalence varies greatly depending on the age of the population [6,13-18,26-33]. Our IFA study showed that the prevalence of the four anti-S IgG antibodies among this general Chinese population were slightly higher than those in another study from Germany using an Escherichia coli BL21-expressed recombinant N-based line immunoassay [13], which reported that the seropositivities in 25 healthy blood donors were $48 \%$ for $\mathrm{HCoV}-\mathrm{HKU} 1,52 \%$ for -OC43, $56 \%$ for $-229 \mathrm{E}$, and $60 \%$ for $-\mathrm{NL} 63$. On the other hand, the seropositivity rate of three individual $\mathrm{HCoVs}$ excluding HCoV-HKU1 in this study was lower than that in another study of a US metropolitan adult population using baculovirus-expressed recombinant N-based ELISA [14], which showed seropositivity rates of $90.8 \%$ for $\mathrm{HCoV}$ OC43, 91.3\% for $-229 \mathrm{E}$, and $91.8 \%$ for $-\mathrm{NL} 63$, while that for-HKU1 was $59.2 \%$. It was also supposed that the significantly different seropositivity rates for the various HCoVs might result in individuals with different demographic factors (e.g. ethnicity, smoking status, and socioeconomic status) having different susceptibilities to individual HCoVs [14]. A recent study of 105 older adult veterans with underlying chronic obstructive pulmonary disease at seven US sites showed that serum IgG to HCoV-229E, -NL63, and -OC43 was detected in at least $98 \%$ of subjects, while antibodies to -HKU1 were identified in 96 subjects (91\%) [17]. Thus EIA assays that use whole virus or $\mathrm{N}$ protein as the antigen, using which apparent cross-reactivity of $\mathrm{HCoV}$ antibodies has been demonstrated previously $[18,24]$, may detect group- rather than type-specific antibody.

Our results regarding anti-S IgG to four individual $\mathrm{HCoVs}$ in children correlate with those of previous seroprevalence studies [6,13-18,26-33], although the data on HCoV-NL63 and -HKU1 were limited. Shao et al. found that antibodies directed to HCoV-NL63 and -229E in children 1 year of age and older were frequently detected using part of the C-terminal region of the $\mathrm{N}$ protein as an antibody capture antigen in an ELISA [15]. A study of children in the Netherlands aged 2.5-3.5 years indicated that $75 \%$ and $65 \%$ of serum samples were positive for antibodies to HCoV-NL63 and -229E, respectively [16]. We observed that the prevalence of these four nonSARS-related HCoV-directed IgG antibodies among children $>1$ year of age were almost identical.

Information on the prevalence of anti-S IgM to nonSARS-related $\mathrm{HCoV}$ is to-date lacking. We first investigated the prevalence of anti-S IgM to four individual $\mathrm{HCoVs}$ among a general population in Beijing using IFA. Anti-S IgM to individual $\mathrm{HCoVs}$ was detected in a portion of the asymptomatic child population. The anti-S
IgM seropositivity appeared to increase with age up to 6 years and decline sharply after 14 years of age. However, no anti-S IgM to individual HCoVs was detected in the healthy adult population. These results suggest that primary seroconversion to these viruses occurs mainly during childhood and youth; In addition, $\mathrm{HCoV}$ infection might result in seroconversion in children with asymptomatic or subclinical manifestations. These results are also in agreement with $\mathrm{HCoV}$ molecular epidemiological surveys $[12,34]$, which have indicated that primary exposure occurs mainly in childhood and youth.

\section{Conclusion}

We conclude that S-based IFA might be a useful specific serological platform for epidemiologic investigation of $\mathrm{HCoV}$ infection. High proportions of children and adults in Beijing show anti-S IgG seropositivity against the four $\mathrm{HCoVs}$, and anti-S IgM antibodies were detected in the sera of asymptomatic children. These four non-SARSrelated $\mathrm{HCoVs}$ appear be circulating in the general population, and sustained $\mathrm{HCoV}$ infection becomes more likely with increasing age. This study may serve as a basis for the prevention and control of non-SARS-related $\mathrm{HCoV}$ infection. However, further research is needed to determine the false-positivity and -negativity rates associated with this anti-S IFA by determining antibody titres during the acute and convalescent phases after primary $\mathrm{HCoV}$ infection. Comparison of serological methods and antigen preparations as well as sample exchange will facilitate validation of the assays for individual $\mathrm{HCoV}$ antibody determination.

\section{Abbreviations}

(HCoVs): Human coronaviruses; (IFA): Indirect immunofluorescence assay; G (lgG): Immunoglobulin; M (IgM): Immunoglobulin; (RT-PCR): Reverse transcription polymerase chain reaction; (SARS): Severe acute respiratory syndrome; (S): Spike.

\section{Competing interests}

The authors declare that they have no competing interests.

\section{Authors' contributions}

TW created the original idea of this research and designed the study. ZW and WW performed experiments. WH and LR provided important data analysis. ZW and TW drafted the manuscript. All authors read and approved the final version of the manuscript.

\section{Acknowledgments}

We thank the Ms Linglin Zhang for samples collection and transport, and the medical and technical staffs from the Peking Union Medical College Hospital for their assistance and support. We also thank all the participants involve in this study for providing samples.

This work was supported by grants from the 973 Program of China (2011CB504704), the State Megaproject for Infectious Disease Research of China (2013ZX1004601) and National 863 Project of China (2007AA02Z464).

Received: 4 December 2012 Accepted: 27 August 2013

Published: 16 September 2013

\section{References}

1. Lai MMC, Perlman S, Anderson LJ: Coronaviridae. In Fields virology. 5th edition. Edited by Fields BN, Knipe DM, Howley PM. Philadelphia: Lippincott Williams \& Wilkins Press; 2007:1305-1335. 
2. Hamre $D$, Procknow JJ: A new virus isolated from the human respiratory tract. Proc Soc Exp Biol Med 1966, 121:190-193.

3. Tyrrell DA, Bynoe ML: Cultivation of a novel type of common-cold virus in organ cultures. Br Med J 1965, 1:1467-1470.

4. van der Hoek L, Pyrc K, Jebbink MF, et al: Identification of a new human coronavirus. Nat Med 2004, 10:368-373.

5. Woo PC, Lau SK, Chu CM, et al: Characterization and complete genome sequence of a novel coronavirus, coronavirus HKU1, from patients with pneumonia. J Virol 2005, 79:884-895.

6. Greenberg SB: Update on rhinovirus and coronavirus infections. Semin Resoir Crit Care Med 2011, 32:433-446.

7. Drosten C, Gunther S, Preiser W, et al: Identification of a novel coronavirus in patients with severe acute respiratory syndrome. N Engl J Med 2003, 348:1967-76.

8. Ksiazek TG, Erdman D, Goldsmith CS, et al: A novel coronavirus associated with severe acute respiratory syndrome. N Engl J Med 2003, 348:1953-66.

9. Bermingham A, Chand MA, Brown CS, et al: Severe respiratory illness caused by a novel coronavirus, in a patient transferred to the United Kingdom from the Middle East, September 2012. Euro Surveill 2012, 17(40):pii $=20290$.

10. Brian DA, Baric RS: Coronavirus genome structure and replication. Curr Top Microbiol Immunol 2005, 287:1-30.

11. Dare RK, Fry AM, Chittaganpitch M, Sawanpanyalert P, Olsen SJ, Erdman DD: Human coronavirus infections in rural Thailand: a comprehensive study using real-time reverse transcription polymerase chain reaction assays. $J$ Infect Dis 2007, 196:1321-1328.

12. Gaunt ER, Hardie A, Claas ECJ, Simmonds P, Templeton KE: Epidemiology and clinical presentations of the four human coronaviruses 229E, HKU1, $\mathrm{NL63}$, and OC43 detected over 3 years using a novel multiplex real-time PCR method. J Clin Microbiol 2010, 48:2940-7.

13. Lehmann $\mathrm{C}$, Wolf $\mathrm{H}, \mathrm{Xu}$ J, et al: A line immunoassay utilizing recombinant nucleocapsid proteins for detection of antibodies to human coronaviruses. Diagn Microbiol Infect Dis 2008, 61:40-88.

14. Severance EG, Bossis I, Dickerson FB, et al: Development of a nucleocapsid-based human coronavirus immunoassay and estimates of individuals exposed to coronavirus in a U.S. metropolitan population. Clin Vaccine Immunol 2008, 15:1805-1810.

15. Shao X, Guo X, Esper F, Weibel C, Kahn JS: Seroepidemiology of group I human coronaviruses in children. J Clin Virol 2007, 40:207-213.

16. Dijkman R, Jebbink MF, El Idrissi NB, et al: Human coronavirus NL63 and 229E seroconversion in children. $J$ Clin Microbiol 2008, 46(7):2368-73.

17. Geoffrey JG, Gira BP, Joseph NV, Theresa ZO: Prevalence of antibodies to four human coronaviruses is lower in nasal secretions than in serum. Clin Vaccine Immunol 2010, 17(12):1875.

18. Maache M, Komurian-Pradel F, Rajoharison A, et al: False-positive results in a recombinant severe acute respiratory syndrome-associated coronavirus (SARS-CoV) nucleocapsid-based western blot assay were rectified by the use of two subunits (S1 and S2) of spike for detection of antibody to SARS-CoV. Clin Vaccine Immunol 2006, 13:409-414.

19. Giménez LG, Rojas J, Rojas A, Mendoza J, Camacho AG: Development of an enzyme-linked immunosorbent assay-based test with a cocktail of nucleocapsid and spike proteins for detection of severe acute respiratory syndrome-associated coronavirus-specific antibody. Clin Vaccine Immunol 2009, 16(2):241-5.

20. Yang ZY, Nabel GJ, et al: A DNA vaccine induces SARS coronavirus neutralization and protective immunity in mice. Nature 2004, 428:561-564.

21. Zhang L, Nolan E, Kreitschitz S, Rabussay DP: Enhanced delivery of naked DNA to the skin by non-invasive in vivo electroporation. Biochim Biophys Acta 2002, 1572:1-9.

22. Garbino J, Crespo S, Aubert JD, et al: A prospective hospital-based study of the clinical impact of non-severe acute respiratory syndrome (non-SARS)-related human coronavirus infection. Clin Infect Dis 2006, 43:1009-1015.

23. Haynes $L M$, Miao C, Harcourt $\mathrm{L}$, et al: Recombinant protein-based assays for detection of antibodies to severe acute respiratory syndrome coronavirus spike and nucleocapsid proteins. Clin Vaccine Immunol 2007, 14(3):331-3.

24. Woo PC, Lau SK, Wong BH, et al: False-positive results in a recombinant severe acute respiratory syndrome-associated coronavirus (SARS-CoV) nucleocapsid enzyme-linked immunosorbent assay due to $\mathrm{HCoV}-\mathrm{OC} 43$ and $\mathrm{HCOV}-229 \mathrm{E}$ rectified by Western blotting with recombinant SARS-CoV spike polypeptide. J Clin Microbiol 2004, 42:5885-5888.
25. Woo PC, Lau SK, Wong BH, et al: Differential sensitivities of severe acute respiratory syndrome (SARS) coronavirus spike polypeptide enzyme-linked immunosorbent assay (ELISA) and SARS coronavirus nucleocapsid protein ELISA for serodiagnosis of SARS coronavirus pneumonia. J Clin Microbiol 2005, 43(7):3054-8.

26. Chan CM, Tse H, Wong SS, et al: Examination of seroprevalence of coronavirus HKU1 infection with S protein-based ELISA and neutralization assay against viral spike pseudotyped virus. J Clin Virol 2009, 45:54-60.

27. Chan CM, Woo PC, Lau SK, et al: Spike protein, S, of human coronavirus HKU1: role in viral life cycle and application in antibody detection. Exp Biol Med (Maywood) 2008, 233:1527-1536.

28. Bradburne AF, Bynoe ML, Tyrrell DA: Effects of a "new" human respiratory virus in volunteers. Br Med J 1967, 3:767-769.

29. Bradburne AF, Somerset BA: Coronative antibody tires in sera of healthy adults and experimentally infected volunteers. J Hyg (London) 1972, 70:235-244

30. Callow KA, Parry HF, Sergeant M, Tyrrell DA: The time course of the immune response to experimental coronavirus infection of man. Epidemiol Infect 1990, 105:435-446.

31. Hasony HJ, Macnaughton MR: Prevalence of human coronavirus antibody in the population of southern Iraq. J Med Virol 1982, 9(3):209-16.

32. Kraaijeveld CA, Reed SE, Macnaughton MR: Enzymelinked immunosorbent assay for detection of antibody in volunteers experimentally infected with human coronavirus strain 229 E. J Clin Microbiol 1980, 12:493-497.

33. Hofmann H, Pyrc K, van der Hoek L, Geier M, Berkhout B, Pohlmann S: Human coronavirus NL63 employs the severe acute respiratory syndrome coronavirus receptor for cellular entry. Proc Natl Acad Sci USA 2005, 102:7988-7993.

34. Principi N, Bosis S, Esposito S: Effects of coronavirus infections in children. Emerg Infect Dis 2010, 16:183-188

doi:10.1186/1471-2334-13-433

Cite this article as: Zhou et al.: First infection by all four non-severe acute respiratory syndrome human coronaviruses takes place during childhood. BMC Infectious Diseases 2013 13:433.

\section{Submit your next manuscript to BioMed Central and take full advantage of:}

- Convenient online submission

- Thorough peer review

- No space constraints or color figure charges

- Immediate publication on acceptance

- Inclusion in PubMed, CAS, Scopus and Google Scholar

- Research which is freely available for redistribution 